\title{
Correction to: Clifford Analysis and Related Topics
}

\author{
Paula Cerejeiras, Craig A. Nolder, John Ryan \\ and Carmen Judith Vanegas Espinoza
}

\section{Correction to:}

P. Cerejeiras et al. (eds.), Clifford Analysis and Related Topics, Springer Proceedings in Mathematics \& Statistics 260, https://doi.org/10.1007/978-3-030-00049-3

In an earlier version of these proceedings, the affiliation of the volume editor "Carmen Judith Vanegas Espinoza" was incorrect. This has been corrected. Correct Affiliation: Department of Mathematics and Statistics, ICB, Technical University of Manabí, Portoviejo, Ecuador. The erratum book has been updated with the changes. 